\title{
Toward Responsibility in International Health: Death following Treatment in Rockefeller Hookworm Campaigns, 1914-1934
}

\author{
STEVEN PALMER*
}

Late in October 1926, a poor man from Bucamaranga, Colombia, wrote a letter to the richest man in the world. Juan de la Rosa Quintero Parra informed John D Rockefeller that his ten-year-old son, José Vicente, had "died suddenly as a result of a purge administered by the Bureau of Uncinariasis", the local incarnation of the Rockefeller Foundation's global project to eradicate hookworm disease. The death of the boy, who worked full-time as a streetsweeper for the municipality, had been "a serious blow since he was the only one who contributed to the support of the family consisting of seven young children". Having heard of Mr Rockefeller's generosity, Quintero appealed to him for assistance, thanked him in advance for the attention he would give to the matter, and hoped that Divine Providence would spare the great philanthropist's life for many years to come. He mailed the letter to Rockefeller Foundation headquarters at 61 Broadway in New York City, the same address where, probably unbeknownst to him, bits of his son's organs had been sent following a post-mortem. Quintero Parra's letter came to the attention of either the 84-year-old patriarch or his son, John D Rockefeller, Jr, the Foundation's president. Their executive secretary, F M Read was instructed to make inquiries into the death of the child, José Vicente Quintero. ${ }^{1}$

The men who administered the Rockefeller Foundation's International Health Board (IHB) quickly verified the philanthropy's role in the death. They had just begun to keep a set of files dedicated to such fatalities, for José Vicente Quintero was not the first child to die at the hands of the Rockefeller Foundation following treatment with oil of chenopodium, a vermifuge particularly suited to dislodging hookworms from the gut. John D Rockefeller and his son would have recalled an earlier incident, also in Colombia, when on a terrible October Monday in 1920 seven children between the ages of five and ten, three of them from the same family, died after receiving doses of

(C) Steven Palmer 2010

* Prof. Steven Palmer, Department of History, University of Windsor, 401 Sunset Ave., Windsor, Ontario, Canada N9B 3P4;

e-mail: spalmer@uwindsor.ca

This paper would not have found its way without the generous consideration and advice of Gilberto Hochman, María Carranza, and Louise Palmer. I would also like to thank Alexandra Stern, Catherine Legrand, Darwin Stapleton, and the reviewers and editors of Medical History for positive critical comments. Research for this paper was supported by the
Canada Research Chairs program, the University of Windsor, and a grant in the History of Basic Medical Research from the Rockefeller Archive Center.

\footnotetext{
${ }^{1}$ Juan de la Rosa Quintero Parra to John D Rockefeller, 30 Oct. 1926, and 'Report of case of poisoning by anthelmintic', Bound Volumes (hereafter BV) 27, Record Group (hereafter RG) 5, Rockefeller Foundation Archives (hereafter RFA), Rockefeller Archive Center (hereafter RAC). The quotations are from the translation of the letter; the original is not in the file. D B Wilson to F M Read, 21 Jan. 1927, BV 27, RG 5, RFA-RAC.
} 


\section{Steven Palmer}

chenopodium from a Rockefeller dispenser on the hacienda "Argentina" in the coffee district of Antioquia. ${ }^{2}$ At the time the Rockefeller Foundation pronounced it "one of the most tragic accidents in the history of hookworm treatment". ${ }^{3}$ The medical directors of the IHB were already aware, however, that these deaths were less accident than macabre statistical concentration in a clear pattern of death following treatment with oil of chenopodium that had stalked their global campaign against hookworm disease almost since its inception. Between 1914 and 1934, when the organization ceased using the vermifuge, the IHB documented over 200 deaths from oil of chenopodium intoxication, more than 80 per cent suffered by children twelve years of age and under.

The following pages can be read as an inquiry into the deaths of people around the world, most of them children, who were fatally poisoned by an ill-advised dosage of this first mass medication of international health. A number of scholars of Rockefeller public health have commented on isolated cases to underscore the potential dangers of the treatment for hookworm disease, or to call attention to the callous official response to such deaths (most often the victims or their poor health were blamed). ${ }^{4}$ I explain why these fatalities occurred regularly over two decades, and explore the changing ways that the IHB and the Rockefeller Foundation reacted to them. The internal investigation into José Vicente Quintero's death, and subsequent debate within the Foundation and the IHB over organizational responsibility and the propriety of compensating the father, also point us to a broader issue raised by the chenopodium fatalities: the evolution of the philanthropy's engagement with harmful outcomes caused by their international public health programmes.

The IHB was not operating in an ethical or legal vacuum, but neither did its officers have at their disposal a ready-made normative framework for international treatment and research. On the surface, and in formal terms, the organization elided the question by conforming to the norms of the foreign jurisdictions in which they operated. Informally, however, senior administrators and field supervisors worked out modes of therapeutic and experimental treatment with oil of chenopodium that, if amorphous, contradictory and motivated more by expediency than morality, traced an early pattern of ethical choices made by an international medical agency. An analysis of the oil of chenopodium files reveals an organizational structure that had no mechanism for effectively translating scientific evidence into safer field protocol. These problems were magnified by what we might call the "meta-experimentalism" of Rockefeller International Health, a dimension nicely revealed in the chenopodium files. Because the IHB hookworm eradication programme was itself conceived as an open-ended experiment, all treatment was understood as involving an experimental dimension. Those who died from overdoses of chenopodium were, in this sense, victims of a loose, multi-purpose and vaguely articulated global experiment whose objectives were simultaneously about everything in

\footnotetext{
2 'Report on seven deaths among twelve cases of chenopodium poisoning in Colombia', RG 5, series 3, box 27, folder 164, RFA-RAC.

${ }^{3}$ Wilbur A Sawyer, 'Memorandum to the General Director: deaths following the administration of anthelmintics in Colombia', BV 27, RG 5, RFARAC.
}

\footnotetext{
${ }^{4}$ Anne-Emanuelle Birn, Marriage of convenience: Rockefeller international health and revolutionary Mexico, Rochester, NY, University of Rochester Press, 2006, pp. 87-8; Soma Hewa, Colonialism, tropical disease and imperial medicine: Rockefeller philanthropy in Sri Lanka, Lanham, MD, University Press of America, 1995, pp. 81, 86.
} 


\section{Toward Responsibility in International Health}

general to do with modern medical approaches to health. Both the parent Rockefeller Foundation and its IHB were at first reluctant to acknowledge responsibility for the unfortunate outcomes of their vast philanthropic benevolence. Internal dynamics associated with institutional maturation, however, and pressures from below in foreign jurisdictions, made officers of both organizations aware of the operational shortcomings that were behind the deaths from chenopodium poisoning among children. This process came to a head in the late 1920s with the inquiry into the death of José Vicente Quintero, a ten-year-old streetsweeper from Barrio la Guacamaya, Bucamaranga, and the eventual compensation of his family.

\section{How Rockefeller Philanthropy Came to Treat José Vicente Quintero}

The prototype of Rockefeller public health philanthropy was launched to treat hookworm disease in the southern United States from 1909 to 1913, after the affliction was identified as a prime reason for the alleged backwardness of the region and its people. When the Rockefeller Foundation was created in 1913 with the specific intent of developing an international programme, treating hookworm disease was deemed the perfect "entering wedge" due to the presence of the infection in a global band that coincided with many tropical territories of increasing interest to the United States. Within three years the IHB had established operations in dozens of territories around the world, with an initial concentration of efforts in Latin America and the British Caribbean, but quickly expanding into many other parts of the tropical world. The New York office of the IHB went through two main phases over the twenty-year period covered in this article. During the initial tenure of Wickliffe Rose (1913-23), though its international operations were extensive, the head office was staffed by a small group of individuals. The director managed supervisors in the field with surprisingly little assistance, and appointed scientific experts ad hoc to study particular issues or conduct surveys of work underway in the field. The second directorship, under the former military doctor, Frederick Russell, was characterized by a larger office with stricter lines of authority, greater managerial division of labour involving specialists in statistics and recordkeeping, and a commitment to continuous public health research by a dedicated laboratory division and the expert evaluation of results from field operations. This model crystallized in 1927-28 and the institution, renamed the International Health Division, emerged triumphant following a power struggle among senior Rockefeller officers, the legitimacy of its growing research and training role recognized by the Foundation. ${ }^{5}$

The IHB quickly expanded its repertoire after 1914, in particular into malaria and yellow fever research and prevention, but treating hookworm disease remained the staple of many of its most ambitious operations, including that in Colombia, until the early 1930s. The Rockefeller Foundation hoped the hookworm campaigns would train local political and medical elites in the principles and benefits of organized public health so that the

\footnotetext{
${ }^{5}$ Raymond B Fosdick, The story of the Rockefeller Foundation, 2nd ed., New Brunswick, NJ, Transaction, 1989, pp. 44-7; John Farley, To cast out
}

disease: a history of the International Health Division of the Rockefeller Foundation (1913-1951), Oxford University Press, 2004, pp. 158-67. 


\section{Steven Palmer}

work would carry on after the IHB programmes ended. To promote this, the agreements with governments embedded the hookworm missions within appropriate host state bureaucracies, and scheduled the gradual transfer of fiscal responsibility to local treasuries. Pointing out how treatment of hookworm disease on a mass scale could improve the productivity of rural labourers often helped mobilize political and economic support for public health, but there were other important motivations. The campaigns were also seen as ideal vehicles for popularizing the notion that microorganisms caused disease, that laboratory-based medicine could detect and treat such disease, and that modern hygiene had many virtues, among them defecating in a toilet and so avoiding the dispersal of hookworm ova. Children were always prime targets of the hookworm campaigns, in part because they were seen as most likely to be receptive to the new message of modern hygiene. ${ }^{6}$

Hookworm disease, also known as ankylostomiasis and uncinariasis, is a soiltransmitted helminthiasis. Hookworm larvae invade a human host on contact with skin, usually the soft tissue between the toes of those who go barefoot. They complete their life cycle as they travel through the body, then attach themselves to the intestinal mucosa of the duodenum and jejunum, and suck blood. The effect is essentially cumulative - that is, the more hookworms lodged in the system, the greater the loss of blood to the point that an iron deficiency anaemia may set in with severe, even fatal, effects. Sufferers feel listless, experience disorienting symptoms of irregular blood flow, and become more susceptible to other diseases. The presence of hookworms, and an idea of the degree of infection, can be detected through microscopic examination of a stool sample for ova, and someone suffering infection can usually be "cured" fairly cheaply and effectively with treatment by vermifuge followed by a purge. ${ }^{7}$ What separates hookworm disease from hookworm infection is difficult to define precisely since the effects of an identical number of worms in a human body will vary considerably according to the height, weight, nutritional

\footnotetext{
${ }^{6}$ On the Rockefeller Sanitary Commission in the US South, see John Ettling, The germ of laziness: Rockefeller philanthropy and public health in the new South, Cambridge, MA, Harvard University Press, 1981. On the initial stages of the IHB hookworm project, see Steven Palmer, 'Migrant clinics and hookworm science: peripheral origins of international health, 1840-1920', Bull. Hist. Med., 2009, 83 (4): 676-709; Marcos Cueto (ed.), Missionaries of science: the Rockefeller Foundation and Latin America, Bloomington, IN, Indiana University Press, 1994; Farley, op. cit., note 5 above; idem, Bilharzia. a history of imperial tropical medicine, Cambridge University Press, 1991, pp. 72-80; Fosdick, op. cit., note 5 above. Among case studies are Christian Brannstrom, 'Polluted soil, polluted souls: the Rockefeller hookworm eradication campaign in São Paulo, Brazil, 1917-1926', Hist. Geog., 1997, 25: 25-45; Rita Pemberton, 'A different intervention: the International Health Commission/Board, health, sanitation in the British Caribbean, 1914-1930', Caribbean Q., 2003, 49 (4): 87-103; Ligia María
}

Peña Torres and Steven Palmer, 'A Rockefeller Foundation health primer for U.S.-occupied Nicaragua, 1914-1928', Can. Bull. Med. Hist., 2008, 25 (1): 43-69; Warwick Anderson, Colonial pathologies: American tropical medicine, race, and hygiene in the Philippines, Durham, NC, Duke University Press, 2006, pp. 194-206.

${ }^{7}$ Z S Pawlowski, G A Schad, G J Stott, Hookworm infection and anaemia: approaches to prevention and control, Geneva, World Health Organization, 1991, pp. 3-5; Richard W Ashford and William Crewe, The parasites of homo sapiens: an annotated checklist of the protozoa, helminhths and arthropods for which we are home, London and New York, Taylor and Francis, 2003, pp. 69-70; David I Pritchard, R J Quinnell, P J Hotez, J M Hawdon and A Brown, 'The immunobiology of hookworm infection', in Celia V Holland and Malcolm W Kennedy (eds), The geohelminths: Ascaris, Trichuris and hookworm, Boston, Dordrecht, and London, Kluwer Academic Publishers, 2002, pp. 143-65. 
condition and concurrent health problems of the host. People can have a considerable degree of infection and remain asymptomatic. Nevertheless, rather than treating those with clear signs of hookworm disease, the Rockefeller Foundation's IHB campaigns involved a standardized treatment regimen for all those found to have any degree of infection. This was justified according to the logic of eradication, and it dovetailed with the goals of health promotion because it submitted the largest possible number of people to the ritual of medical treatment following examination and diagnosis. ${ }^{8}$

It is far from certain, then, that José Vicente Quintero suffered from hookworm disease when he was given his fatal dose of oil of chenopodium in a cup of panela (brown sugar diluted in water). The doctor's report noted that eggs of the hookworm parasite had been found in his stool sample and that he displayed an anaemic condition of the skin and conjunctiva, symptomatic of anaemia. Nevertheless, the ten-year-old weighed 25 kilos and seems to have been in reasonably good health, his diet considered "common among people of his class", and his medical history, in the opinion of the physicians who oversaw his case, was free of malnutrition or diseases like malaria or beriberi. ${ }^{9}$ Many of the other children who died from overdoses of this potentially lethal vermifuge were also probably not suffering from hookworm disease. This is not to say that there was no medical reason to treat them. Unlike the case with other worms like Ascaris, the greatest pathology from hookworm infection was found in adults, but hookworm disease comes on through worm accumulation, so ridding a host body of the parasite reduces the imminent likelihood of suffering hookworm disease. Moreover, ankylostomiasis can result in permanent malformation of a growing body, and for this reason a case could be made for keeping children as free of the parasite as possible. ${ }^{10}$

Still, as soon became apparent, removing hookworms from children using oil of chenopodium was a very risky business. The IHB had campaigned in the US South and through the first year of international operations using thymol, a vermifuge that had been standard for treating hookworm since the 1880s. ${ }^{11}$ A powerful phenol extracted from thyme or made synthetically, thymol was problematic because its side effects included nausea, dizziness and vomiting, and it, too, could occasionally be fatal. The risks of treatment with thymol during the campaigns in the US South, as well as the fact that patients, especially children, found it noxious and avoided taking it, had made many Rockefeller men anxious to develop a vermifuge that would be at once safer and

\footnotetext{
${ }^{8}$ On this point, see Ilana Löwy, “"Intervenir et représenter": campagnes sanitaires et élaboration des cartographies de l'ankylostomiase', Hist. Phil. Life Sci., 2003, 25: 349-50.

9 'Report of case of poisoning by anthelmintic', BV 27, RG 5, RFA-RAC. For a portrait of what a poor working boy's life in a small Latin American city might have been like at this time, see the autobiographical sketch by Carlos Luis Fallas (b. 1909), 'Autobiografía', Marcos Ramirez, 4th ed., San José, Editorial Costa Rica, 1986, pp. 9-11; the
}

book, originally published in 1952 as Marcos Ramírez: aventuras de un muchacho, is a delightful, lightly fictionalized memoir of Fallas' childhood on the streets of San José, Costa Rica, 1915-1924.

${ }^{10}$ Pritchard, et al., op. cit., note 7 above, p. 147.

${ }^{11}$ Ettling, op. cit., note 6 above, p. 25; and Rockefeller Foundation (hereafter RF)-IHB, 'Introduction', Bibliography of hookworm disease, New York, RF, 1922, pp. xxii-xv; also, pp. 327-56 on publications on anthelmintics for hookworm, 1880-1921. 


\section{Steven Palmer}

more palatable, and effective. ${ }^{12}$ In the early twentieth century pharmacologists became interested in vermifuges made from the chenopodium plant. The volatile oil distilled from the fruit of Chenopodium anthelminticum, a roadside weed common in the US (known as Baltimore Oil or American wormseed oil), had always been in the US pharmacopoeia and long been effectively used in domestic medicine as an anthelmintic in roundworm infections in children. ${ }^{13}$ Increasing attention to hookworm disease around the world motivated further research into alternatives to thymol. ${ }^{14}$ The IHB itself commissioned Samuel Darling and Joseph Barber in 1914 to study the use of chenopodium in hookworm treatment in British colonial South-East Asia. Before their study was completed the world war interrupted the supply of thymol, and IHB supervisors in the field simply started to use oil of chenopodium instead of thymol because it was available and inexpensive. $^{15}$

With this in mind, a number of studies were undertaken in the US, and their results suggested that the vermifuge had potential, but was probably dangerous. ${ }^{16}$ The warnings were more than offset by a very promising report from Victor Heiser, a senior official with the US Public Health Service in the Philippine Islands who had just joined the IHB as its "Director of the East". ${ }^{17}$ In May 1915 he presented findings based on the use of oil of chenopodium in over 100,000 cases in the hospitals of South-East Asia for hookworm and other intestinal parasites. There, despite grave reservations about the use of oil of chenopodium, "heretofore ... owing to its tendency to produce untoward effects and even death", physicians had been forced to employ it because of the wartime scarcity and expense of thymol. Heiser had plumbed the reports of British medical officials who had used it in many treatments, and found not a single fatality. ${ }^{18}$ Notably, the data were based on treatment given in hospital facilities where the oversight of medical personnel was constant, and few of the patients were children.

Against this sketchy and ambiguous backdrop, and knowing that circumstances had led its mission supervisors to adopt the drug on the ground, the directors of the IHB

\footnotetext{
${ }^{12}$ Ettling, op. cit., note 6 above, pp. 228n.12, 165-7; Farley, op. cit., note 5 above, p. 41n. On children's distaste for thymol, Daniel M Molloy, 'Second annual report on work for the relief and control of uncinariasis in Nicaragua for the period January 1st 1916 to December 31st 1916', p. 23, RG 5, series 3, box 150, folder 1787, RFA-RAC.

${ }^{13}$ A K Bond, 'Death after wormseed', Maryland M. J., 1897, 37: 289-90.

${ }^{14}$ The chemistry of oil of chenopodium was studied in the US by Edward Kremers and E K Nelson of the bureau of chemistry at the US Department of Agriculture. Dutch tropical disease researchers, H Vervoort and Wilhelm Schüffner, based on research in the Netherlands East Indies, presented a paper to the 1912 International Congress on Hygiene and Demography in Washington, DC, advocating the superiority of chenopodium in the treatment of hookworm disease. See Murray Galt Motter, Hookworm disease: the use of oil of
}

chenopodium in its treatment, Washington, Government Printing Office, 1914, p. 2.

${ }^{15}$ Rockefeller Foundation, Annual report, 1915, pp. 214-21.

${ }^{16}$ Robert M Levy, 'Oil of chenopodium in the treatment of hookworm infections', JAMA, 1914, 43 (22): 1946-9; also in this vein was Motter, Hookworm disease (see note 14 above). Motter worked in the Division of Pharmacology of the United States Public Health Service.

${ }^{17}$ On this controversial character, see Farley, op. cit., note 5 above, pp. 12-13; Anderson, op. cit., note 6 above, pp. 180-205; and his own memoirs, Victor Heiser, An American doctor's odyssey: adventures in forty-five countries, New York, W W Norton, 1936.

${ }^{18}$ Victor Heiser, 'Report upon the experiences of physicians in the Orient with oil of chenopodium in the treatment of over 100,000 cases of uncinariasis and other intestinal parasitic diseases', pp. 1, 5, RG 5, series 2 , box 63 , folder 408, RFA-RAC. 
approved trial use of oil of chenopodium in the Central American and British Caribbean hookworm programmes. "Experiments" in Guatemala, Costa Rica, and Nicaragua on upwards of 10,000 people produced "favorable" to "excellent" results. The drug seemed less trying on the patients, and because oil of chenopodium was so effective in expelling roundworms - unlike hookworms, "plainly visible to the naked eye"-it produced "a strong psychic effect", considered "a decided advantage in favor of this drug". ${ }^{19}$ Widespread use of oil of chenopodium in 1916 led to reports of "alarming symptoms, and sometimes death" in the Southern United States, Panama, Nicaragua, Ceylon and Egypt, even though standard doses had been used. The heads of the IHB concluded from that year's data that "extreme caution in the use of the drug is therefore indicated until its proper method of preparation has been learned, its chemical composition and stability standardized, and a safe dosage and method of administration established". Rather than issuing formal regulations, however, they urged mission supervisors to be "extremely discriminating in its use". ${ }^{20}$

A reduction in dosage in subsequent years appeared to reduce the incidence of poisoning, but the cases that did occur confirmed another worrisome tendency pointed out in the pre-1915 literature: three-quarters of those affected were children of twelve and under. None the less, the IHB directors felt that oil of chenopodium had such great anthelmintic value, not only for hookworm but for roundworm and other parasites, "that the desirability of discovering methods for its safe employment justifies additional effort". ${ }^{21}$ This process of discovery would take place in day-to-day campaigning, using a drug and a methodology that the Foundation and the IHB directors understood was not safe, with the children of Latin America, the Caribbean, Asia and the southern United States as experimental subjects. The informal experiment widened: operations were begun in 1917 in countries with large populations like Brazil, Ceylon and India.

In 1919, the IHB launched a major hookworm campaign in Colombia. It gradually worked through the most populous parts of the country, getting under way in Bucaramanga in 1925. On 13 July 1926, after hookworm ova were found in the stool of José Vicente Quintero, the child streetsweeper was given a first dose of oil of chenopodium mixed with carbon tetrachloride and a purge with no undue effects. Eight days later, as was the norm in the Colombian campaigns, he was subjected to a second round of treatment, receiving ten drops of oil of chenopodium in two batches, at 6.30 and 8.00 a.m., and a purge of sulphate of magnesia an hour later. Death from an overdose of oil of chenopodium followed a typical course, and the death of José Vicente Quintero was terribly typical. ${ }^{22}$ The second dose of vermifuge soon sent him into neurotoxic shock, and he began to vomit and exhibit signs of mental confusion and weakness. His pulse accelerated, and he became progressively weaker until he fell unconscious. By

\footnotetext{
${ }^{19}$ Rockefeller Foundation, Annual report, 1915, pp. 214-16.

${ }^{20}$ Rockefeller Foundation, Annual report, 1916, pp. 220, 246-7.
} 


\section{Steven Palmer}

4.30 in the afternoon the boy was in convulsions and his vomit had become foamy. He died a few minutes later. ${ }^{23}$

\section{Grim Tally}

In 1926, just prior to the death of José Vicente Quintero, the information gatherers at the New York office of the IHB collated existing records and established two registries detailing deaths following treatment for hookworm disease with oil of chenopodium. One series, going back to 1915 and eventually stretching to 1934, contained incidents in which the oil was the sole vermifuge, and documented 129 deaths involving treatment by agents of the IHB. The other series, covering the period 1922-33, registered deaths following treatment by oil of chenopodium-carbon tetrachloride mixture, and catalogued 69 fatalities involving the Rockefeller missions. ${ }^{24}$ Taken together, the books register 195 deaths following treatment with oil of chenopodium or with carbon tetrachloridechenopodium mixture. Over four-fifths (150, or 81 per cent) of those who died, and whose age was recorded, were children twelve years of age or younger. The bound volumes, however, do not account for all recorded fatalities. For example, of 56 such Brazilian deaths reported by the mission supervisor, Lewis Hackett, in 1921, only 29 appear in the bound compendia (again, the sad tally of children was notable: 43 of the 49 whose age was recorded were less than ten years old when they died). Such an important discrepancy suggests that a full count of those who died following IHB treatments, and whose death was reported in some form by its agents to the head office, would require a review of all quarterly reports and associated correspondence from all jurisdictions. The sheer volume of records involved makes such a review impractical.

The data in the bound volumes is uneven. Some deaths are exhaustively documented with autopsy reports and correspondence between mission supervisors and field workers, reiterated in a 'Chronological table of contents' that tabulates vital statistics, and gives the interval from treatment to death, symptoms, and officers reporting. With some deaths in the field, possibly in remote areas, or at the hands of unreliable field workers, there are no supporting documents; all that appears is the entry in the chronological table: "1919-2 cases-Brazil;" or "Coolie-Ceylon". ${ }^{25}$ Other deaths following treatment may well have gone unrecorded, through either negligence or denial. Supervisors virtually always rejected the idea that the medicine could have been responsible for a death in the field. Instead they looked immediately to patient non-compliance with the instructions for taking either the vermifuge or the purgative (in José Vicente's case, the boy was blamed for eating a fruit on the day of the treatment). ${ }^{26}$ They might also shrug off the

\footnotetext{
23 'Report of case of poisoning by anthelmintic', BV 27, RG 5, RFA-RAC.

${ }^{24}$ Confusingly entitled 'Deaths following treatment, vol. 1, 1915-1934', and 'Deaths following treatment, 1922-1933, vol. 1', the progeny of the binders is not known. It can be inferred that they were both begun just prior to 1 November 1926 due to comments made in the frontispiece. The volumes are currently catalogued as 'Deaths following treatment, vol. 1, 1915-1934', BV 27, and 'Deaths following
}

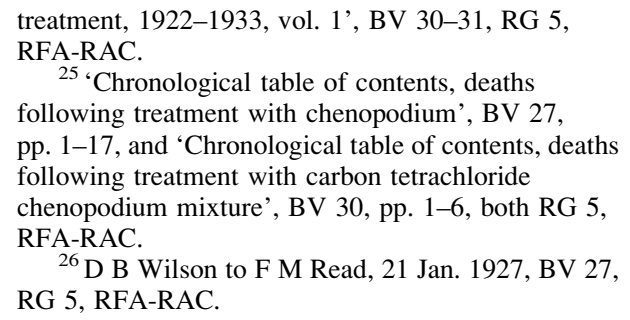
following treatment with chenopodium', BV 27, pp. 1-17, and 'Chronological table of contents, deaths following treatment with carbon tetrachloride chenopodium mixture', BV 30, pp. 1-6, both RG 5, RFA-RAC.

${ }^{26}$ D B Wilson to F M Read, 21 Jan. 1927, BV 27, RG 5, RFA-RAC. 


\section{Toward Responsibility in International Health}

death as inevitable due either to severe malnutrition or to the severity of the hookworm infection in the patient. Generally, the victim was recast as having been fatally ill- had it not been the medicine, it would have been something else. On some occasions, doubts were cast on the pharmaceutical quality of the vermifuge, and sometimes on the competence of the "native" dispensers. Given this culture of denial, the pressure that dispensers were under, and the powerlessness of some of the populations treated, it is conceivable that dispensers occasionally suppressed information about deaths when circumstance permitted. $^{27}$

Other deaths may simply have gone unnoticed in the carnage that was estate labour. José Vicente Quintero was a municipal employee from a family whose father, while poor, was literate, able to get a Catholic burial for his child, and dogged in his pursuit of accountability under Colombian law and custom. In a legalistic proto-democracy like Costa Rica, the death in 1917 of a Hispanic mestizo child in the rural hinterland following treatment with oil of chenopodium led to the arrest, incarceration, and trial of the technical assistants who administered the drug; in the end a good lawyer ensured they would be exonerated by the judge, but there was no possibility that the connection between the death and hookworm treatment would go unregistered. ${ }^{28}$ The same could not be said if an indigenous child on a Guatemalan coffee estate suffered death following treatment by a local or foreign white medical officer. This may explain why not a single report of death following treatment with oil of chenopodium was registered in Guatemala during the years 1915-21, when over 100,000 people were treated, almost exclusively migrant indigenous workers (including women, children and infants) toiling on large coffee estates. ${ }^{29}$ A 1917 visit by an experienced IHB officer noted that there had been many cases in Guatemala of toxic symptoms, but insisted there had been no fatalities from oil of chenopodium. ${ }^{30}$ This seems unlikely.

In any case, the data from the bound volumes, in combination with the fatalities reported by Hackett, register 222 deaths from oil of chenopodium poisoning by the IHB between 1914 and 1934; 193 (87 per cent) of the dead were children under thirteen years of age. In a 1921 communiqué to the Brazilian bulletin of the National Academy of Medicine, Hackett used his data to advance a mortality rate of 1:46,000 in the use of oil of chenopodium, and argued that this was low if compared to general anaesthesia with ether $(1: 16,000)$, diphtheria antitoxin, or salvarsan. ${ }^{31}$ However, Hackett was using figures for the number of treatments, not the number of people treated, and he did not provide a separate calculation for the under-thirteen age grouping. So, for example, in the

\footnotetext{
${ }^{27}$ Two deaths that occurred in Nicaragua in 1919 were attributed by the supervisor to severity of hookworm disease in one case, and to malnutrition in the other; see D M Molloy, 'Report on work for the relief and control of hookworm disease in Nicaragua from September 22, 1915 to December 31, 1920', p. 13, RG 5, series 2, box 34, folder 202, RFA-RAC. For Mexican responses of this kind, see Birn, op. cit., note 4 above, p. 87.

${ }^{28}$ Louis Schapiro to Wickcliffe Rose, 17 March 1916, RG 5, series 1.2 , box 29 , folder 450 , RFARAC.
}

\footnotetext{
${ }^{29}$ Emmett I Vaughan, 'Report on work for the relief and control of hookworm disease in Guatemala from March 15, 1915 to December 31, 1920', p. 6, RG 5, series 2, box 31, folder 184, RFA-RAC.

${ }^{30} \mathrm{M}$ E Connor, 'Notes on Guatemala', n.p., 2 June 1917, RG 5, series 2, box 31, folder 184, RFARAC

${ }^{31}$ Excerpt from communication from Dr Hackett to bulletin of National Academy of Medicine, Brazil, 1921, 93 (2).
} 


\section{Steven Palmer}

Brazilian campaign in 1919 there was a mortality rate of one for every 21,000 people treated; in 1920, one for every 15,000 treated. In hookworm operations throughout Latin America, children twelve and under accounted for roughly 30 per cent of those treated for hookworm infection. Given that 80 per cent of chenopodium poisoning fatalities were registered in this group, then in the first instance we would be speaking of a mortality rate of about 1:9,000, in the second about 1:6,400 children under thirteen treated with oil of chenopodium. These rates were alarming for an infection that was not necessarily causing harm in the person receiving treatment, and when research was making it increasingly clear that the risks of treating children with oil of chenopodium, especially using the dual-dose method favoured by the IHB, were unacceptably high.

\section{Pharmacological and Ethnopharmacological Blinders}

By the time José Vicente Quintero swallowed his second, fatal dose of chenopodium a mere eight days after the first treatment, the extreme risk he was incurring was well established in medical literature, much of it produced in association with IHB researchers. One year earlier, in 1925, for example, the IHB director Frederick Russell asked the staff researcher, Samuel Darling, to review a similar death, that of a seven-year-old in Puerto Rico following a second treatment after seven days. Darling responded, "I am convinced that the interval between chenopodium treatments should be longer." He cited to Russell the work that had been done on this subject at the request of the IHB itself, perhaps underlining his frustration by adding a reference to a medical primer.

We realized in the Orient that the drug was a neurotoxin and that it was cumulative in its effects.... Attention has been called to this danger in the report of the Uncinariasis Commission to the Orient, in the 'Treatment of Hookworm Infection,' Journal of AMA, Febr. 1918, and in Publication no. 9. In the article on hookworm disease reprinted from the Nelson Loose-Leaf Medicine page 486 it is stated ... "that a period of 10-14 days should elapse between treatments, and preferably one month." 32

Indeed, much of the research on oil of chenopodium should have been cause for serious concern to an organization involved in the mass treatment of poor, rural dwellers suffering anaemia and malnutrition. An important 1917 study by William Salant, a senior pharmacologist in the US Department of Agriculture's chemistry bureau, judged that this highly "active" and "toxic" drug had a tendency to affect the central nervous system, heart, respiratory system, digestive organs and kidneys, and that "in hepatic and gastrointestinal diseases it may likewise prove more toxic". He also flagged the likely importance of nutritional condition in determining the toxicity of oil of chenopodium. ${ }^{33}$ This was followed in early 1918 by publication of the results of the IHB-sponsored experiments in the Malay peninsula, the most extensive research yet on the effects of the

\footnotetext{
${ }^{32}$ Samuel Darling to Frederick Russell, 12 Sept. 1925 BV 27, RG 5, RFA-RAC.

${ }^{33}$ William Salant, 'The pharmacology of the oil of chenopodium with suggestions for the prevention and treatment of poisoning', JAMA, 15 Dec. 1917, 69
}

(24): 2016-17. Another study that determined that chloroform was more effective against hookworm, was Maurice C Hall and Winthrop D Foster, 'Oil of chenopodium and chloroform as anthelmintics', JAMA, 30 June 1917, 68 (26): 1961. 
drug on human subjects. The authors found that oil of chenopodium could "quite possibly" have a cumulative action, leading to deep and prolonged coma, followed by death, when repeated treatments were given within a week. ${ }^{34}$ Another 1918 study using data collected from autopsies on two patients who had died following treatment by IHB teams in Panama argued that oil of chenopodium should not be administered to patients suffering from a high grade of anaemia - the defining symptom of hookworm disease. ${ }^{35}$ Each successive study proposed a longer interval between the first and second treatments to avoid cumulative neurotoxicity.

Complicating the picture even further is the possibility that, in many cases, what IHB officers took to be their first administration of oil of chenopodium might actually have had the effect of a second dose in a short interval due to the ethnopharmacological practices of the rural populations under treatment in the Americas. A concoction of the chenopodium plant had been used as a vermifuge in domestic medicine for hundreds of years. As early as 1570 the Spanish king's medical emissary to the New World, Francisco Hernández had written that the indigenous people of Mesoamerica expelled harmful animals from their bellies with a decoction made from the roots of epazotl. ${ }^{36}$ The eminent botanist, Henri Pittier noted in his 1908 botanical guide to Costa Rica that Chenopodium ambrosoides, locally known as "Apazote", grew commonly in the dry areas around houses, and was used in popular medicine to make an infusion that was mixed with castor oil. "From all parts of the plant an essential oil is extracted that is ... used to expel lumbrici, by taking a few drops in a lump of sugar." ${ }^{37}$ IHB supervisors were quite aware of this. The Guatemalan director of hookworm operations noted in 1915 that "the Indians know chenopodium well under the name of Epázotl". 38 A hookworm manual for Costa Rican staff remarked that oil of chenopodium was a volatile oil distilled from local plants whose use was "very common in South America". 39

In Guatemala, a local agent commissioned by the IHB in 1919 to advise them on such practices in an indigenous area, reported that all children were dewormed each full moon, a coincidence of de-worming and the full moon noted elsewhere in Central America. ${ }^{40}$ Though little is known about how widespread or regular such domestic

\footnotetext{
${ }^{34}$ Samuel T Darling, M A Barber and H P Hacker, 'The treatment of hookworm infection', JAMA, 23 Feb. 1918, 70 (8): 499, 504.

${ }^{35}$ David A Roth, 'Some dangers of the chenopodium treatment', South. Med. J., Nov. 1918, 11 (11): 733-4.

${ }^{36}$ Sandra L Orellana, Indian medicine in highland Guatemala: the pre-Hispanic and colonial periods, Albuquerque, NM, University of New Mexico Press, 1987, p. 109. See also John K Crellin and Jane Philpott, A reference guide to medicinal plants: herbal medicine past and present, Durham, NC, Duke University Press, 1990, pp. 269-70, which notes that the vernacular name "American wormseed" (also referred to as Jerusalem oak, oak of paradise, wormseed, Mexican tea, and pigweed) was used for various chenopodium species, notably Chenopodium botrys - a confusion over taxonomy due to hybridization and the "morphological plasticity of
}

character" of Chenopodium ambrosoides var. anthelminticum. See also Julia F Morton, Atlas of medicinal plants of Middle America, Bahamas to Yucatan, Springfield, Charles C Thomas, 1981, p. 176.

${ }^{37}$ Henri Pittier, Ensayo sobre plantas usuales de Costa Rica, Washington, DC, H L and J B McQueen, 1908, pp. 60-1.

${ }^{38}$ Draft notes for first quarter report from Guatemala, 1915, p. 4. RG 5, series 3, box 140, folder 1653, RFA-RAC.

${ }^{39}$ República de Costa Rica, Reglamento del Depto de Ankylostomiasis, n.p., n.d. [Imprenta Nacional, 1917], p. 17; copy found in RG 5, series 2, box 28, folder 170, RFA-RAC.

${ }^{40} \mathrm{~J}$ W Burres, 'Report for the first quarter-Guatemala, 1919', RG 5, series 3, box 140, folder 1657, RF-RAC. Deworming on the full moon was also noted by the IHB officer in rural Panama; 


\section{Steven Palmer}

medical practices were, it is possible that many children received a "first dose" of chenopodium for hookworm from IHB dispensers dangerously soon after a dose of domestic chenopodium for roundworm. The domestic, actual first dose would likely have been much weaker than the IHB "first dose"-a late-nineteenth-century Baltimore doctor had distinguished between the domestic remedy and "the oil of wormseed, prepared by the manufacturing pharmacists", which was a much more powerful drug and which common people were wary of due to its toxic effects. ${ }^{41}$ Nevertheless, according to Crellin and Philpott's reference guide to medicinal plants in the Americas, even the milder domestic vermifuge, once widely used in the rural United States, could be toxic on enough occasions that it was abandoned over the nineteenth century in favour of safer vermifuges. $^{42}$

Moreover, patent vermifuges with a stronger chenopodium base may have been supplanting homemade preparations in domestic medical practice. As Molloy, the Nicaraguan director, put it in 1916, "Chenopodium anthelminticum (?) is a very common plant in all Central America, being known by the common name Apazote. Concoctions made from the seeds, pods and flowers of this plant are prescribed by the 'curanderos' in the treatment of all sorts of intestinal disorders, and its vermifugal action is known to all. In fact, referring to it as a vermifuge, it is called 'Tiro Seguro'-our familiar 'Dead Shot'." 43 Oil of chenopodium-based patent medicines using the same name were mentioned in the reports of at least two cases of fatal poisoning of children in Colombia following first treatment with the oil. In 1928 in Santander del Norte, not far from where José Vicente Quintero died, four-year-old Trinidad Navarro suffered a similar death from poisoning. The physician, Dr G A Suárez, medical chief of the field unit, noted that the child had no chronic ailment, but had been treated over the course of the previous year by a number of patent vermifuges, among them "Angelito", "Vencedor", and "Tiroseguro". One week later, in the same locale, five-year-old Julián Garces, who had also taken patent worm medicine over the previous year, died from chenopodium poisoning. The reports on their deaths did not propose any link with a prior dose of oil of chenopodium in the patent vermifuge, nor did the covering letter by the regional director, Hector Howard. ${ }^{44}$

It is possible that popular knowledge of the toxic effects of chenopodium helped lessen the risk of poisoning by the IHB. People may have found ways to keep their children from being treated, or ceased deworming when they knew the hookworm teams were moving through their area. A late 1916 report from Molloy suggests the way that information about the hookworm medicine circulated. "I have personally heard the criticism that we were using 'quack medicine' ('medicina de curandero') more than once." His

see Lewis Hackett to his mother, 14 Oct. 1914, Hackett Papers, RFA-RAC; and Lewis Hackett to Wickliffe Rose, 7 Sept. 1914, RG 5, series 3, box 152, folder 1832, RFA-RAC. De-worming at the time of a full moon may be related to an ancient empirical appreciation of the lunar periodicity of reproduction in invertebrates, including worms; see George Sarton, 'Lunar influences on living things', Isis, 1939, 30 (3): $425-51$, p. 505. In Nicaragua many people also thought the moon a factor in the operation of the purgative accompanying the vermifuge; see Molloy, op. cit., note 12 above, p. 23.

${ }^{41}$ Bond, op. cit., note 13 above.

${ }^{42}$ Crellin and Philpott, op. cit., note 36 above, p. 270.

${ }^{43}$ Molloy, op. cit., note 12 above, p. 28.

44 'Deaths following treatment, 1922-1933', BV 30, RG 5, RFA-RAC. 
report also shows, however, that populations undergoing treatment might be wilfully misled. "It was at first thought that this familiarity with the drug might be turned to advantage; but later experience has proved that here, as elsewhere, 'familiarity breeds contempt'. The advantages of disguising the drug are not to be underestimated." Molloy endorsed mixing oil of chenopodium with eucalyptus oil to mask the identity of the "specific drug". 45

\section{Disconnected Experimentalism}

A peculiarity of the IHB model was its inherent and constant experimentalism. This was related to, but went beyond, the basic sense in which, for many medical doctors of the time, all instances of therapy were an experiment. First of all, the programme was itself an experiment, something inscribed in the very first agreement between the IHB and the colonial authorities of British Guiana: "to cooperate in trying out an experiment ... to approximate, as nearly as practicable, complete eradication of the disease within a selected area". ${ }^{46}$ And though that programme was explicitly understood as a pilot project, virtually every phase of hookworm work, as it extended itself into more and more areas of the globe, was conceived by its makers as the next experimental step in a public health programme that was itself so novel as to be one large experiment. This impulse to approach all treatment as experiment was shared by IHB officers at every level, from the general director in New York to the mission supervisors and their assistants on the ground. It dovetailed with an organization that was recruiting young, research-oriented physicians from a reformed medical school system that emphasized the scientific identity of physicians; almost without exception, advancement in the IHB ranks depended on further research-based education within this evolving complex, most often graduate work in public health at Johns Hopkins, a programme established under Rockefeller auspices. ${ }^{47}$ This culture of experimentalism, one might say, was in the organization's "genetic code".

Yet it had no clear connection to the development of field protocol, something that had fatal consequences in the case of chenopodium use. For example, formal IHB experiments in field conditions in Brazil between 1918 and 1920 by Samuel Darling and W G Smillie had led them to question whether the agency should be dispensing oil of chenopodium to children at all. They were surprised to see that "strong vigorous children certainly sometimes react very rapidly and alarmingly to the drug", 48 Smillie's main publication contained the programmatic sub-heading, 'Should Young Children be Treated for Hookworms?' The answer for children under five was never with oil of chenopodium. "The difficulty of their treatment and the danger to the child outweigh any advantage to be gained by the removal of their few worms." For those five to eight years

\footnotetext{
${ }^{45}$ Molloy, op. cit., note 12 above, p. 28.

${ }^{46}$ Rockefeller Foundation, Annual report, 1913-14, p. 71.

${ }^{47}$ Elizabeth Fee, Disease and discovery: a history of the Johns Hopkins School of Hygiene and Public Health, 1916-1939, Baltimore,
}

\footnotetext{
Johns Hopkins University Press, 1987, pp. 165-6.

${ }^{48}$ S T Darling and W G Smillie, Studies on hookworm infection in Brazil, First Paper, New York, Rockefeller Institute for Medical Research, 1921, p. 36.
} 


\section{Steven Palmer}

of age, his determination was that they should be given only a small dose of chenopodium if they suffered from roundworms and other parasites. "One should NOT treat them with the full dose of chenopodium in order to remove their hookworms. Children of 8 years or less are particularly susceptible to the toxic effects of cheno or other anthelmintics." ${ }^{49}$ Despite the centrality of these researchers to the scientific culture of both the IHB and the Rockefeller Institute for Medical Research, their findings were never used to revise approaches in the field-indeed, the vast majority of deaths from chenopodium poisoning between 1922 and 1934 occurred in children under eight years old, and a number in infants of two years and less; in Guatemala (where no fatalities were ever reported) until at least the end of 1919 infants less than one year old were given chenopodium. ${ }^{50}$

The casual manner in which field protocol was developed, and its disconnection from a scientific canon, is evident in the reports of Daniel Molloy. Molloy conducted "trials" and "experiments" on oil of chenopodium from 1916 to the end of 1920, ranging from using different dosages to combining the drug with other vermifuges or alternate purges. He regularly guided himself by his own experience in the Philippines, and made reference to a wide variety of studies in the medical literature to support his methodology and rationale. Molloy also took it upon himself to develop his own safeguards, translating an article by Salant into Spanish for distribution to the staff. ${ }^{51}$ His reports are a testament to the lack of protocol governing innovation in the field. In line with the new research orientation of medical and public health education in the United States, the report shows that local supervisors were allowed and encouraged to be public health scientists with some licence to use the population under treatment as experimental subjects for tests aimed at improving key components of the IHB's methodology and therapy. They also enjoyed considerable autonomy in designing and carrying out those experiments even though they might involve serious risk, as in the case of experiments with vermifuges.

These rather amorphous notions of experimental design, authority, and objectives were characteristic of the medical and public health research context in the US at this time. As Harry Marks has shown, the first two decades of the twentieth century were notable for a diversity of research sites-research institutes, hospitals, government laboratories, specialty clinics and universities - that "permitted researchers to 'experiment' with various strategies for linking the scientific work of the laboratory with the problems seen in the clinic". 52 We can add the disparate international sites of IHB hookworm treatment

\footnotetext{
${ }^{49}$ Wilson G Smillie, Studies on hookworm infection in Brazil, 1918-1920, Second paper, New York, Rockefeller Institute for Medical Research, 1922, pp. 21-2; capitalization in original.

50 'Chronological table of contents-oil of chenopodium', and 'Chronological table of contents - carbon tetrachloride-chenopodium mixture'; W T Burres, 'Report on work for the relief and control of hookworm disease in Guatemala from March 15, 1915, to December 31, 1919', pp. 5-7, RG 5 , series 2 , box 31 , folder 184 , RFA-RAC.
}

\footnotetext{
${ }^{51}$ Daniel M Molloy, 'Report on work for the relief and control of hookworm disease in Nicaragua from September 22, 1915 to December 31, 1920', p. 14, RG 5, series 2, box 34, folder 202, RFA-RAC; also see Molloy, op. cit., note 12 above, pp. 24-30.

${ }^{52}$ Harry M Marks, The progress of experiment: science and therapeutic reform in the United States, 1900-1990, Cambridge University Press, 1997, p. 47.
} 


\section{Toward Responsibility in International Health}

to this quilt. Sometimes particular sites were designated for formal experimentation in which "clinical material" and other factors could be more rigorously controlled, and specific research objectives explored, as in the case of Smillie and Darling's work in São Paolo. But just as Simon Flexner, the scientific director of the Rockefeller Institute for Medical Research, held the notion that "the hospital was, after all, a laboratory", there was a strain in the research culture of the IHB that saw the vast rural clinic of its global hookworm operations in the same way. ${ }^{53}$

The scarce regulation of protocol for field experimentation or administration of vermifuges was also a reflection of the overall decision making culture of the IHB, which John Farley has characterized as "ad hoc and haphazard" and lacking in "long-term planning". ${ }^{54}$ Both qualities are evident in a 1921 letter from Wickliffe Rose to the supervisor of operations in Panama. Rose rather chattily wrote, "our experience as a whole would seem to confirm your own conclusions that, all things considered, chenopodium is the drug to use". He went on to cite Darling and Smillie's recent Brazil research results, noting that "they tend to confirm the dosage previously described" and adding, "incidentally", that the resulting publications would be sent along to him. In this case, the very director of the IHB acted as a highly subjective conduit for in-house research results reaching field supervisors. Notably, his comment on dosage failed to mention that the research of Darling and Smillie called into question whether oil of chenopodium should be given to children at all. The implicit message was that the local supervisor was free to draw his own conclusions, though he might want to compare them to more extensive data to be mailed along later. ${ }^{55}$

This is not to say that the IHB or the Rockefeller Foundation was passive in the face of the hookworm deaths. From the very beginning the Foundation brought fatal episodes to light and discussed them in their annual reports. The directors of the IHB organized studies on the best methods for administering the drug. Local mission supervisors conducted their own experiments, took steps to address perceived problems following fatal incidents, and acted to ameliorate the negative operational and public relations impact as well as to ensure that no further deaths would occur while the campaign finished in a particular region. New methods and reduced dosages for children were introduced in an uneven fashion in a number of hookworm campaigns, and a new mixture of chenopodium and carbon tetrachloride was tried out. This apparently led to a gradual reduction in the incidence of fatal poisoning.

The Information Section's own statistics show that from 1921 to 1924 the rate of treatments per death improved notably over the 1917-20 period (from 39,346 to 82,729 ), as did the rate of persons treated per death (from 22,172 to 47,243). ${ }^{56}$ This may have reflected a growing maturity and normalization in IHB procedures. During Rose's tenure (1913-23), experimental studies like those of Darling and Smillie were carried out at the bidding of International Health, but under the auspices

\footnotetext{
${ }^{53}$ The 1905 quote from Flexner is cited in Marks, ibid., p. 50.

${ }^{54}$ Farley, op. cit., note 5 above, p. 19.
}

\footnotetext{
${ }^{55}$ Wickliffe Rose to Fred C Caldwell, 7 Feb. 1921, RG 5, series 3, box 153, folder 1843, RFA-RAC.

${ }^{56} \mathrm{C}$ Williamson to Frederick Russell, 13 March 1925, BV 27, RG 5, RFA-RAC.
} 


\section{Steven Palmer}

of the Rockefeller Institute for Medical Research. The subsequent Russell era, with an in-house laboratory research branch, continued to register a drop in the frequency of fatalities from oil of chenopodium. Nevertheless, how new scientific knowledge was debated and transformed into policy remains unclear for both periods, and in neither phase, it seems, were local supervisors instructed to follow the conclusions of the IHB scientific experts or issued clear protocols on the administration of oil of chenopodium.

\section{Responsibility}

In 1926 a grieving father's letter prodded both the Rockefeller Foundation and the IHB to confront the issue of their responsibility in these deaths. The Quintero file circulated slowly from the top to the bottom of Foundation headquarters at 61 Broadway, and up and down the IHB chain of command from New York and New Orleans to Bogotá and Bucamaranga, growing with every stop. The president of the Rockefeller Foundation, George E Vincent, while insisting that the case was "legally and logically" not one of liability, noted that there were questions of "good will and international feeling" involved. He prefaced his submission of the matter to the Foundation's lawyer, Thomas Debevoise, with the comments: "It is a rather distressing case. If we begin to grant indemnities for accidents of this kind it would be a precedent which would give trouble. On the other hand, to refuse to do anything has certain unfortunate implications." 57 A concatenation of questions, then, would dictate the consideration of the petition: from legalistic issues of malfeasance, liability and precedent, to the vagaries of international "good will" and unspecified negative consequences, all wrapped around a case of undeniable human suffering.

The IHB's hookworm campaigns were inserted into foreign states and governed by their respective laws. As Hector Howard, the veteran director for the Caribbean area wrote when asked to weigh in on the Quintero case, "The examination and treatments for hookworm are carried forward under orders and regulations issued by the Chief Health Officer of Colombia. This being true there is no obligation on the part of the Rockefeller Foundation or the Division of the Foundation [the IHB] to grant the request [of the boy's father for compensation]." ${ }^{58}$ Quintero Parra had, in fact, first gone to the alcalde (state-appointed mayor with some judicial authority) of Bucamaranga and laid a complaint on the death of his son. Depositions were taken from the two Colombian physicians directing the local campaign, and from a neighbour who was willing to swear that the boy had eaten a tropical fruit on the day of his treatment, hastening his own death by disobeying the strict instructions to fast. The case was dropped. ${ }^{59}$ As the cursory investigation and quick exoneration suggests, the labouring peoples of the Latin American, Caribbean and South Asian territories in which the hookworm programmes

\footnotetext{
${ }^{57}$ George E Vincent to Thomas Debevoise, 2 April 1929, BV 27, RG 5, RFA-RAC.

${ }^{58}$ Memorandum from Hector H Howard, 21

March 1929, BV 27, RG 5, RFA-RAC.
}

${ }^{59}$ D B Wilson to F M Read, 21 Jan. 1927, BV 27, RG 5, RF-RAC. 


\section{Toward Responsibility in International Health}

took place were at this time kept, to one degree or another, from the full enjoyment of rights in cases of this kind.

Despite enjoying such broad surrogate authority, however, the IHB did not take it for granted, or use it to impose the hookworm treatment on rural peoples. With some exceptions, the institution made systematic efforts to inform not just elites at all levels of society, but also the prospective subjects of treatment, about the nature and objectives of their programme. Written information was circulated explaining the disease and its treatment in some detail, using both technical and popular medical terminology (though not necessarily without a measure of obfuscation or deception, as evidenced in Molloy's decision to hide the identity of the vermifuge). House-tohouse visits were conducted, often in the company of regional and village notables, to assuage doubts and offer further explanation. There were two principal motivations for this conduct. The overarching IHB objective in the hookworm campaigns was to convince common rural people of the benefits of modern medicine and hygiene, so coercive treatment was avoided whenever possible. In very practical terms, the IHB determined that greater coverage could be achieved with fewer resources if rural populations cooperated with the campaigns.

Still, because the history of international medical ethics prior to the Second World War has not been well studied, it is worth reflecting on the ethical dimensions of IHB conduct during the hookworm campaigns. ${ }^{60}$ In the early-twentiethcentury United States, according to Susan Lederer, norms of medical ethics were clearer than is often believed. Claude Bernard's 1865 statement of principle of medical and surgical morality - that no experiment should be done on a person if it might be at all harmful, not even if the results could advance scientific knowledge or be of benefit to others-was one such accepted norm. Lederer also underlines the widespread approval in the US medical community for William Osler's 1907 dicta that every new procedure should have clear therapeutic benefit, patient consent should be secured before experimental trials, prior testing on animals should be done to establish "absolute safety" for man, and doctors should not experiment on patients in their care unless direct benefit to the individual was likely to follow. ${ }^{61}$ As for the need to effect a certain treatment on particular individuals or groups, Martin Pernick has shown how a utilitarian calculus that weighed the issue of risk versus benefit had become characteristic of US medical practice by the late nineteenth century. ${ }^{62}$

Such considerations would have been the main ethical reference points for the IHB doctors recruited for administration, research and foreign fieldwork. Many came from the rejuvenated US military medical service and the US Public Health Service. The mission to eradicate hookworm was formed in the image of the yellow fever work

\footnotetext{
${ }^{60}$ Robert Baker, 'The history of medical ethics', in W F Bynum and Roy Porter (eds), Companion encyclopedia of the history of medicine, London and New York, Routledge, 1993, vol. 2, pp. 852-97, on pp. 871-2.

${ }^{61}$ Susan E Lederer, Subjected to science: human experimentation in America before the Second World
}

War, Baltimore, Johns Hopkins University Press, 1995, pp. 1, 11-12.

${ }^{62}$ Martin A Pernick, A calculus of suffering: pain, professionalism, and anesthaesia in nineteenthcentury America, New York, Columbia University Press, 1985. 


\section{Steven Palmer}

undertaken in Cuba and Panama, and Walter Reed's pioneering programme to establish informed consent during the yellow fever inoculations in Havana was part of their inheritance. Others were products of the new medical training culture of the United States, in which Osler was a central reference point. Even closer to home, the Rockefeller Institute for Medical Research-administratively separate from International Health, but under a shared umbrella of medical philanthropy and whose research resources were mobilized by the IHB between 1913 and 1923-had been in the sights of US anti-vivisectionists since its creation. In 1912 Hideyo Noguchi, one of its prominent researchers, had received a great deal of negative publicity for experiments conducted on children, including orphans, in an effort to develop a diagnostic test for syphilis. ${ }^{63}$

The actions of IHB scientists and field supervisors corresponded to this heterogeneous and elastic ethical map. Darling and Smillie's experiments in Brazil are a good case in point. Smillie had a long history of using incarcerated populations as experimental subjects, both inside the US and abroad, and it was typical that he sought out a population of wage labourers on a coffee plantation in Brazil to conduct his experiments. Not only was the study designed to ensure that the experimental subjects were essentially without rights by choosing "large coffee plantations in isolated communities" where "the colonists are under strict discipline" and the plantation owners highly cooperative, it was clearly designed to test limits. ${ }^{64}$ As the authors wrote about oil of chenopodium, "We have had a good opportunity to observe its toxic effects, for we have given the maximum dose a great many times in the test treatment." ${ }^{65}$ Not surprisingly, three deaths from chenopodium poisoning were clinically documented during their year of experimentation, one of an eightyear-old girl.

Because the programmes were embedded in local state institutions and operated under local public health laws, the most important sanction was that which came from the political and medical elites of the countries and territories where hookworm operations were taking place. Given the nationalist and anti-imperialist sentiments of a growing portion of this community, the IHB had to step lightly due to its association with a name that was synonymous with US capitalism. Witness Hackett's submission to Brazil's National Academy of Medicine, mentioned earlier, in an attempt to reassure leading medical figures that there was no problem with oil of chenopodium because its risks were well within established medical norms. ${ }^{66}$ The ethical sanction of the local medical community was especially important precisely because IHB missions were not staffed by US nationals operating with some sort of diplomatic immunity; other than the director, staff for hookworm operations were

\footnotetext{
${ }^{63}$ Lederer, op. cit., note 61 above, pp. 11-12.

${ }^{64}$ Samuel Darling and W G Smillie, 'Report of field research work on hookworm infection of the Institute of Hygiene, Part 1', p. 2, RG 5, series 2, box 23, folder 138, RFA-RAC. On Smillie's experimental approach, see Farley, op. cit., note 5 above, pp. 161-2. The Brazilian experiments are discussed
}

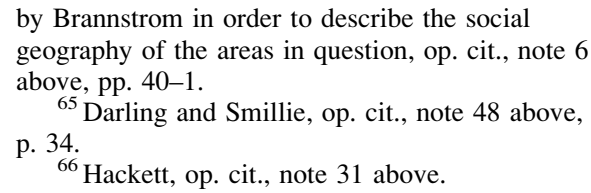


recruited from among local physicians and dispensers who were often professional, intellectual and moral authorities at the regional or national level. The importance of this is evident in the response to the Quintero death, where the medical supervisor of the hookworm campaign in the Santander region, Dr Rafael Uscátegui Mantilla, pressed the Rockefeller Foundation to address the father's claim, and informed them for the first time of a precise sum, 100 pesos (that he had perhaps negotiated). In a letter of January 1929 the eminent physician from a clannish Bucamaranga community of doctors reiterated the blameless nature of the death, but underlined that "this misfortune has been most cruel" to a man who was "in extreme poverty". He informed the Foundation that he wished to "add my request to that of Quintero, an unfortunate workman, for the purpose of making him sympathetic toward the Foundation instead of bearing a grudge". 67

The conjuncture and setting clearly helped to motivate a consideration of Quintero Parra's—and Uscátegui's—request. By the late 1920s the IHB had given more hookworm treatments in Colombia than in any other place in its worldwide operations (some 2.5 million treatments to 1.362 million people). Colombian physicians had displayed some medical nationalist irritation about the scale and style of the IHB's intervention, and this had spilled over into a dispute over the interpretation of a yellow fever outbreak, one of whose scenes was played out in Bucamaranga in 1923. The mid- to late-1920s was also a time of increasing anti-US feeling in Colombia, which took on a specifically anti-Rockefeller tinge in protests and labour action in 1924, and again in 1927, against the Tropical Oil Company, a subsidiary of Standard Oil, the corporate flagship of Rockefeller enterprises. This in turn was part of a general period of social unrest in Colombia between 1926 and 1929 that peaked in a banana strike against another symbol of US imperial capital, the United Fruit Company, and an infamous massacre in Ciénega of striking workers by the army in December of $1928 .^{68}$ The stormy context may have been part of the reason that the letter caught the attention of John D Rockefeller, and could explain Vincent's thoughts on international good will and the avoidance of "certain unfortunate implications". It might also account for Uscátegui's decision to serve as intermediary for Quintero Parra and press the case with his US employers, after Quintero Parra repeatedly requested compensation and made a "continual clamor" to the "employees who took part in the hookworm campaign". 69

\footnotetext{
${ }^{67}$ Rafael Uscátegui Mantilla to the Rockefeller Foundation, 22 Jan. 1929, BV 27, RG 5, RFA-RAC; on clannish physicians, Max Olaya Restrepo, 'Médicos santandereanos destacados en la primera década del siglo', Crónicas Médicas de Santander, Dec. 1999, 2 (6): 155-9.

${ }^{68}$ Emilio Quevedo, Catalina Borda, Juan Carlos Eslava, Claudia Mónica García, et al., Café y gusanos, mosquitos y petróleo. El tránsito desde la higiene hacía la medicina tropical y la salud pública en Colombia, 1873-1953, Bogotá, Universidad
}

\author{
Nacional de Colombia, 2004, pp. 202-28, 252-5. See \\ also Emilio Quevedo, et al., 'Knowledge and power: \\ the asymmetry of interests of Colombia and \\ Rockefeller doctors in the construction of the concept \\ of “Jungle Yellow Fever", 1907-1938', in Can. Bull. \\ Med. Hist., 2008, 25 (1): 71-109; and Christopher \\ Abel, Health care in Colombia, c.1920-c. 1950: \\ a preliminary analysis, London, Institute of Latin \\ American Studies, 1994, p. 7. \\ ${ }^{69}$ Rafael Uscátegui Mantilla to G Bevier, 11 Sept. \\ 1929, BV 27, RG 5, RFA-RAC.
}




\section{Steven Palmer}

The ethical milieu of US medical education and practice, the growing institutional awareness of the fatalities resulting from a disjuncture between research findings and field protocol, and the moral and political voice of local professional and patient communities, all combined to move the IHB, and the Rockefeller Foundation, toward accepting some measure of responsibility for chenopodium poisonings. This is visible as early as Hackett's 1917 notes on the death of three children under ten in Brazil. The state examiner exonerated the IHB following autopsies, and Hackett attributed the deaths to an "unfortunate accidental conjunction of our treatment with certain pathological conditions which could not have been anticipated". Still, the graduate of Harvard medical school concluded that "the medicine cannot ... be wholly exonerated, and it is believed in the laboratory that Chenopodium is too powerful a depressant for young children when followed after a considerable interval by a saline purgative alone". ${ }^{70}$ An explicit, if offensively jocular recognition of responsibility can be found in comments made by the mission director of the Mexican hookworm programme, Andrew Warren, who had presided in 1926 over a number of fatal poisonings of children following treatment with oil of chenopodium, formally refusing to take responsibility each time with the usual repertoire of arguments. On 15 July of that year, however, Warren boasted in a memorandum sent to the general director, Russell (as it happened, during the interval between José Vicente Quintero's first and second doses), that "the confidence of the people is such that we can kill a member of the family with chenopodium and the other members will demand that they continue to receive their treatment". 71

Coming as it did only three months later, Juan de la Rosa Quintero Parra's petition to John D Rockefeller for compensation for the death of his son suggests a more complicated picture, as does the response of the Rockefeller Foundation and the IHB themselves to the father's request. By 1927 the IHB had its own in-house research facility to evaluate the report on the Quintero death. Wilbur Sawyer, head of the new laboratory, reviewed the file for Russell in March, and reiterated that the interval of eight days between the two treatments of José Quintero was, "I believe, shorter than one can safely use as a routine procedure" (he argued for a minimum lapse of fourteen days). ${ }^{72}$ The Rockefeller Foundation's lawyer approved the idea (initially suggested by the Colombian physician, Uscátegui) of its president, Vincent, of a "small gift, made as you suggest personally by your representative in the Field" as a "good investment". 73 According to the regional director Hector Howard, this was also the wish of "Mr Rockefeller", who instructed the 100 pesos be given to Quintero "as coming from an anonymous party" ${ }^{74}$ Finally, even this disguise was dropped and on 7 September 1929, the cusp of the great global slump,

\footnotetext{
${ }^{70}$ Lewis Hackett, 'Excerpt from 3rd quarter report on activities for the relief and control of uncinariasis in Brazil, from 1 January 1917 to 30 September 1917', p. 4, BV 27, RG 5, RFA-RAC.

${ }^{71}$ Andrew Warren to Frederick Russell, 15 July 1926, RG 5, series 1.2 , box 258, file 3282, RFARAC; cited in Birn, op. cit., note 4 above, p. 88.
}

\footnotetext{
${ }^{72}$ Memorandum to Dr Russell concerning case of anthelmintic poisoning, José V Quintero, p. 2, BV 27, RG 5, RFA-RAC.

${ }^{73}$ Thomas Debevoise to George E Vincent, 5 April 1929, BV 27, RG 5, RFA-RAC.

${ }^{74}$ Hector Howard to G Bevier, 11 July 1929 , BV 27, RG 5, RFA-RAC.
} 


\section{Toward Responsibility in International Health}

Juan de la Rosa Quintero Parra received a cheque for 100 pesos made out in his name on the Bogotá account of the IHB's Anti-anemia Commission. ${ }^{75}$

\section{Conclusion}

It is quite extraordinary (though not atypical for the audacious historical actor in question) that at the very moment it was deploying a new methodology to accompany an unprecedented international intervention, the Rockefeller Foundation's IHB rather casually embarked on a near-total shift in medicinal regime to a vermifuge that was widely considered more dangerous than the previous standard treatment with thymol. Equally amazing and typical, the shift was informally fashioned as an extensive, ongoing evaluation of overall effectiveness of the drug within varying approaches to mass public health treatment. Yet the growing concern of the Foundation and the IHB for these deaths, displayed in their publications and their record-keeping from the outset of the campaigns, shows that its officers were not fully comfortable with the moral shield afforded by their operating according to the laws of other countries. In disparate, only occasionally perceptible, ways this moral unease married with managerial discomfort and a growing ability of actors in foreign jurisdictions to exert pressure, and worked its way through the IHB across the 1920 s.

The nexus of factors played some role in reducing the incidence of fatalities following treatment with oil of chenopodium, and helped to promote more rigorous record keeping on such episodes. In the Quintero case, an institutional determination that scientific knowledge had not been rigorously applied to field protocol, combined with influence brought to bear from below, led this first great actor of international health to the conclusion that responsibility had to be accepted in the event of tragic harm done to the health of patients and their families-even poor ones on the periphery. In this sense, the response of the IHB to the death of José Vicente Quintero, a ten-year-old street sweeper from Bucaramanga, traces an early institutional encounter with issues that would continue to be of concern in the just prosecution of global health: squaring ethical frameworks with scientific findings and operational objectives, formulating strict protocol, avoiding the tendency to value economic and programmatic expediency more than the risk that poor people might suffer, and appreciating the ethno-medical cultures of those who engage, whether they like it or not, the emissaries of biomedical models of health.

By the time Juan de la Rosa Quintero Parra received the money that surreptitiously compensated him for the responsibility of the Rockefeller Foundation for the death of his son, José Vicente, the IHB had mostly given up hookworm campaigning, with the exception of a limited number of programmes in parts of Asia, especially Ceylon, and indeed in Colombia, that carried on until 1934, claiming the lives of nine more poor young souls along the way. For his part, Quintero Parra had no illusions about the nature of the compensation he had received, or its value in the political and

\footnotetext{
${ }^{75}$ Receipt for 100 pesos signed before two witnesses by Juan de la Rosa Quintero Parra, verified
}

by $\mathrm{G}$ Bevier, Colombian mission supervisor, BV 27, RG 5, RFA-RAC. 


\section{Steven Palmer}

moral economy of international health. A month after cashing the cheque, he mailed another letter to New York City, this time directed to "Frederick Russell, MD, The Rockefeller Foundation":

The object of these lines is to give sincere and loyal expression to my deep gratitude for the manner in which you received my humble petition concerning the death of my never-to-be-forgotten son. I bought a cow with the hundred pesos received; it provides us with milk, and every day we think or give utterance to the worthless but eloquent phrase of the beggar: "God will reward you." Please accept my respectful salutations and best wishes for your health and happiness.

Very truly yours,

Juan de la R Quintero Parra ${ }^{76}$

${ }^{76}$ Juan de la R Quintero Parra to Frederick Russell, 12 Oct. 1929, BV 27, RG 5, RFA-RAC. 